\title{
'Spectral fingerprinting' for specific algal groups on sediments in situ: a new sensor
}

\author{
N. Aberle ${ }^{1,2}$, M. Beutler ${ }^{3}$, C. Moldaenke ${ }^{4}$ and K. H. Wiltshire ${ }^{5}$ \\ Max Planck Institute for Limnology, Plön
}

With 8 figures and 2 tables

\begin{abstract}
Currently it is still extremely difficult to adequately sample populations of microalgae on sediments for large-scale biomass determination. We have now devised a prototype of a new benthic sensor (BenthoFluor) for the quantitative and qualitative assessment of microphytobenthos populations in situ. This sensor enables a high spatial and temporal resolution and a rapid evaluation of the community structure and distribution. These determinations are based on the concept that five spectral excitation ranges can be used to differentiate groups of microalgae, in situ, within a few seconds. In addition, because sediments contain a lot of yellow substances, which can affect the fluorescence and optical differentiation of the algae, the device was equipped with a UV-LED for yellow substances correction. The device was calibrated against HPLC with cultures and tested in the field. Our real-time approach can be used to monitor algal assemblage composition on sediments and is an ideal tool for investigations on the large-scale spatial and temporal variation of algal populations in sediments. Apart from the differentiation of algal populations, the BenthoFluor allows instantaneous monitoring of the chlorophyll concentrations and determination of which algae are responsible for this on the uppermost surface of sediments in the field and in experimental set-ups.
\end{abstract}

Key words: pigments, excitation spectra, chlorophyll- $a$, benthic algae, fluorescence.

${ }^{1}$ Authors' addresses: Present address: Leibniz Institute of Marine Sciences (IFMGEOMAR), Düsternbrooker Weg 20, 24105 Kiel, Germany;

E-mail: naberle@ifm-geomar.de

${ }^{2}$ Max Planck Institute for Limnology, August-Thienemann-Straße 2, 24306 Plön, Germany.

${ }^{3}$ King's College London, Randall Division of Cell \& Molecular Biophysics, Guy's Campus, London SE1 1UL, United Kingdom.

${ }^{4}$ bbe Moldaenke, Wildrosenweg 3, 24119 Kronshagen, Germany.

${ }^{5}$ Biologische Anstalt Helgoland, Stiftung Alfred-Wegener Institute for Polar and Sea Research, P. O. Box 180, 27483 Helgoland, Germany. 


\section{Introduction}

Microphytobenthos of marine and freshwater sediments is a diverse assemblage of pro- and eukaryotic autotrophic microalgae. The qualitative and quantitative assessment of this important algal association, which is the main primary producer in shallow, especially intertidal and littoral, coastal ecosystems (Admiraal 1980, Colijn \& De Jonge 1984), is a major scientific challenge. The determination of algal biomass has always been problematic. Since 1890, when HAECKEL, who considered phytoplankton counting a task which could not be accomplished without 'ruin of mind and body', not much has changed and this is even more true for algal biomass on sediments. Until the early $1990 \mathrm{~s}$ microphytobenthos was a poorly studied subject primarily because the methods available to us were few and difficult. As the technology of sampling and analysing microalgal populations in sediments has improved (REVSBECH et al. 1981, Revsbech \& Joergensen 1983, Wiltshire et al. 1997, Paterson et al. 1998, Barranguet \& Kromkamp 2000, Wiltshire 2000, Murphy et al. 2004), studies on microphytobenthos populations have become increasingly popular. However, the fact remains that it is extremely difficult to adequately sample populations of microalgae on sediments and the requirement of differentiating algal populations over large areas for ground-truthing in remote sensing studies is usually difficult to achieve because the sediments are so patchy. Even the improved current methods, although quite accurate, involve rather time consuming enumeration to species or major taxonomic groups using counting chamber methods (UTERMOEHL 1958) or High Performance Liquid Chromatography analyses (WILTSHIRE \& SCHROEDER 1994) of the sediments using microtome methods (WILTSHIRE 2000). Perhaps the greatest problem with these methods is that measurements are not conducted immediately and thus they are retrospect and not suited to instant assays in situ. As a result, it is difficult to detect such aspects as patchiness and algal migration.

Fluorescence-emission measured around $685 \mathrm{~nm}$ is widely accepted as a measure of chlorophyll contents of algae in aquatic systems. Indeed, depth profiling of chlorophyll fluorescence in water bodies has been carried out since the early 1970 s (KIEFER 1973, CULlEN et al. 1997). Since then some attempts have been made to distinguish different algal groups in phytoplankton communities using their fluorescence properties (Yentsch \& YeNTSCH 1979, Yentsch \& Phinney 1985, Kolbowski \& Schreiber 1995, Feron et al. 1993). Some of these fluorescence methods have been adapted for sediments. GoRBUNOv et al. (2000) used FRR (Fast-Repetition Rate) fluorometry to estimate photochemical yield and other photosynthetic parameters of microphytobenthos in situ. KromKamp et al. (1998), BARRAnguet \& KromKamp (2000), SERodio et al. (1997, 2001) and GLud et al. (2002) used PAM (pulse amplitude modulation)-technique (SCHREIBER et al. 1986) to estimate primary productivity and electron transport rates of benthic samples. 
Based on our earlier work with a sensor for pelagic phytoplankton (BEUTLER et al. 2002 a) we set out to devise a prototype of a new benthic method for the quantitative and qualitative assessment of microalgae in situ and, furthermore, with a high spatial and temporal resolution. The development of a multialgal benthic sensor is not documented in the literature so far and it thus presents a novel approach for the assessment of group-specific benthic microalgal assemblages.

\section{Material and results}

\section{Measurement principles}

The colour of a photosynthetic organism is influenced by the pigments of the photosynthetic apparatus. Furthermore, the colour of algae is a useful taxonomic criterion. Various taxonomic groups differ significantly in their fluorescence excitation spectrum. Here, we designate algal groups characterised by similar fluorescence excitation spectra as distinct 'spectral signature groups'. We are able to distinguish four spectral groups (1) Green (chlorophyta): algae containing chlorophyll- $a / b, 2)$ Bluegreen (cyanobacteria): algae containing phycobilisomes rich in phycocyanin, 3) Diatoms: algae containing chlorophyll- $a / c$ and green light absorbing xanthophylls and 4) Cryptophyta: algae containing chlorophyll- $a / c$ and phycoerythrin.

Our concept is based on the fact that fluorescence is emitted mainly by the chlorophyll- $a$ of the photosystem II (PS II) antenna system, which consists of the evolutionarily conserved chlorophyll- $a$ core antenna and species-dependent peripheral antennae. This association results in spectral differences in the fluorescence excitation spectra. Using this method for phytoplankton, BEUTLER et al. 2001, 2002 (a) and 2000 (b) were able to distinguish between four algal groups in situ and could correlate the biomass concentrations of different spectral groups of algae. In BEUTLER et al. 2002 (b) the chlorophyll profiles were corrected for the influence of yellow substances. Yellow substances have a higher absorbance in the UV region than in the visible spectrum. This is different to phytoplankton. Therefore an additional norm spectrum for yellow substances (analogue to the phytoplankton spectrum) can be used in the mathematical fitting procedure to differentiate yellow substances from phytoplankton cells. These determinations are based on the concept that six spectral excitation ranges can be used to differentiate groups of microalgae in situ within a few seconds. In addition, since sediments contain a lot of yellow substances which can affect the optical differentiation of the algae, the device was equipped with a correcting UV-LED for yellow substances.

\section{Design and settings of the submersible instrument}

Because the sediments of interest are often underwater or, as in the intertidal, intermittently underwater, it was important to build an underwater device. The optics and electronics are mounted in a waterproof stainless-steel housing $(1=45 \mathrm{~cm}, \varnothing=14 \mathrm{~cm})$ with a sealed optical fibre bundle ( $5 \mathrm{~m}$ long; $\varnothing=0.9 \mathrm{~cm}$; Zeutec, Germany) extending out to 


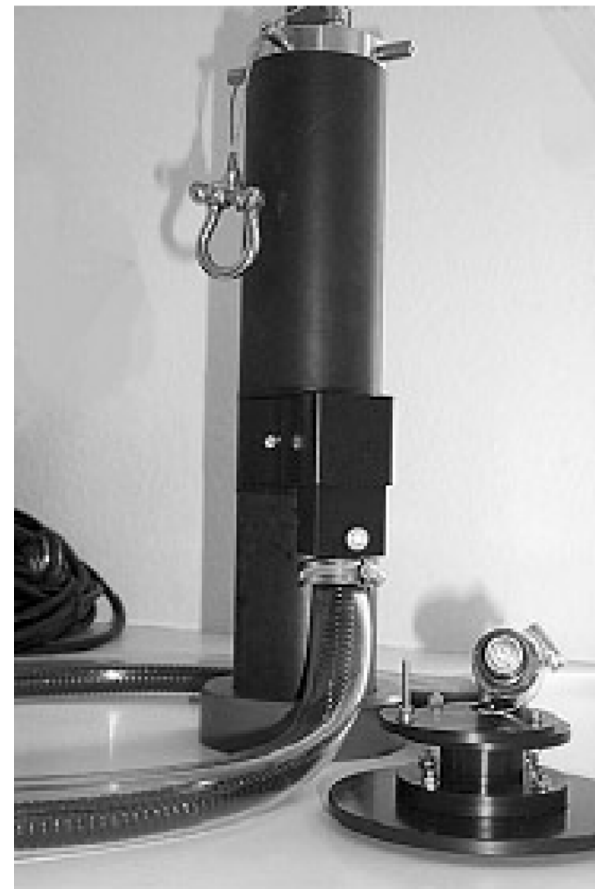

Fig. 1. Photo of the BenthoFluor housed in a water resistant cylindrical case. The fluorometer is connected with a $5 \mathrm{~m}$ long optical fibre to the measuring head. The special disc-shaped measuring chamber is shown in the front. This chamber is placed on top of the sediment and connected to the fibre bundle prior to measurements.

a small light-proof measuring chamber which is placed on the sediment and ensures a constant distance from the sediment surface to the detector bundle (Fig. 1).

Algal chlorophyll- $a$ and yellow substances are excited using light from six LEDs with the following emission wavelengths: $370 \mathrm{~nm}$ (UV-A), $470 \mathrm{~nm}$ (blue), $525 \mathrm{~nm}$ (dark green), $570 \mathrm{~nm}$ (light green), $590 \mathrm{~nm}$ (yellow/orange) and $610 \mathrm{~nm}$ (red). The excitation light is guided through the beam splitter and the fibre bundle (Fig. 2) resulting in a mean light intensity of $4 \mu \mathrm{E} \mathrm{m}^{-2} \mathrm{~s}^{-1}$ at the sample. The light intensity used here had a negligible actinic effect and was not much different to fo light (see van KoOTEN \& SNEL 1990 for nomenclature). The samples were adapted 30 s to further reduce errors in chlorophyll determination caused by different pre-illuminations. The LED light passes through a short-pass filter ( $50 \%$ transmission at $615 \mathrm{~nm}$ DT cyan special, Balzers, Liechtenstein) and a focusing lens. The five light-emitting diodes (LEDs) are switched on sequentially at a frequency of $5 \mathrm{kHz}$. The measuring pulse duration is $0.1 \mathrm{~ms}$. Light intensities were determined at the position of the algal filter with the PhAR sensor Hansatech QRT 1 (Hansatech, UK). Chlorophyll- $a$ fluorescence with wavelengths between $680 \mathrm{~nm}$ and $710 \mathrm{~nm}$ is detected using a photomultiplier (H6779-01, Hamamatsu, Hamamatsu City, Japan) behind a band pass filter (bbe-fk 1, bbe Moldaenke, Kiel, Germany). The photomultiplier signal is digitized by an $\mathrm{AD}$ converter (12-bit $\mathrm{AD}$ conver- 


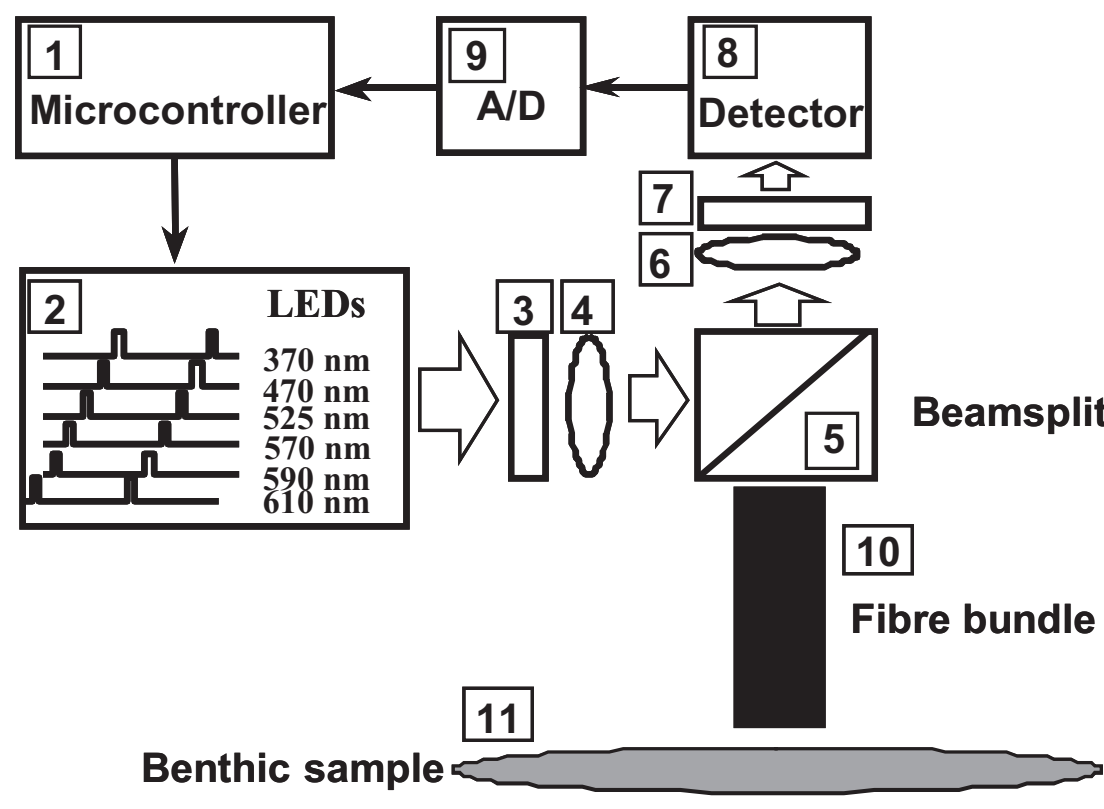

Fig. 2. The BenthoFluor components: (1) microcontroller, (2) six light-emitting diodes, (3) short-pass filter to block red and IR emission, (4) focussing lens ( $=25 \mathrm{~mm}$ ), (5) beamsplitter, (6) focussing lens, (7) band-pass filter, (8) integrated photomultiplier, (9) 12-bit AD-converter (conversion rate of $100 \mathrm{kHz}$ ), (10) fibre bundle and (11) benthic sample.

ter, conversion rate: $100 \mathrm{kHz}$ ) and processed by the same microcontroller (MM-1035CAQ 18, Phytec, Mainz, Germany) used for controlling the LEDs.

Data can be stored in the probe or transferred directly to a PC, or for field measurements, a handheld data logger. High sensitivity and dynamic range are extremely important as the light is transmitted to and from the sediment surface via a sealed optical fibre enabling measurement of fluorescence excitation spectra at low chlorophyll concentrations. During measurement the probe can either be in water or, as in the intertidal, in air. It is found that the fluorescence intensity from the same benthic sample reduces in air by $\sim 20 \%$ in comparison to a measurement in aqueous medium (due to changes in refractive index and absorption). It is thus necessary to measure fluorescence in either air or water for a given study to ensure that the measurements are comparable.

For large-scale spatial assessments of the benthic microflora, for example in the intertidal, the probe can additionally be equipped with a backpacking device, allowing the user to carry the BenthoFluor easily leaving the users hands free for the fibre bundle and the measuring chamber. The spectra are recorded automatically with an integration-time of a second. 


\section{Calibration procedure}

\section{Pre-calibration}

The basic running parameters of the BenthoFluor were initially calibrated against a bench-top multialgal fluorometer. It was, as described above, precalibrated for algal group differentiation using suspensions of planktonic microalgae used by the company bbe Moldaenke in their fluorometer calibrations. These were for the green spectral group: Chlorella vulgaris (Chlorophyta); blue spectral group: Synechococcus leopoliensis (cyanobacteria); and for the brown spectral group: Cyclotella meneghiniana (diatoms). The mixed group (Cryptophyta) were excluded in this investigation because of their rarity in the benthic samples. These algae were first measured in a suspension using a cuvette multialgal fluorometer (bbe Moldaenke), then filtered onto GFF-filters (Whatman) and measured by the probe. For general information on calibrating a multialgal fluorometer see also details in BEUTLER et al. 2001, 2002 $(\mathrm{a}, \mathrm{b})$. The known chlorophyll quantities on the filter (given in $\mu \mathrm{g}$ chlorophyll$a \mathrm{~cm}^{-2}$ calculated from the solutions' chlorophyll content measured by the cuvette multialgal fluorometer in relation to the filter surface area) were set against the fluorescence response of the instrument (Fig. 3).

The filtrate was also measured to check that all the algae were retained on the filters. In the measurement procedure described above, relative intensities

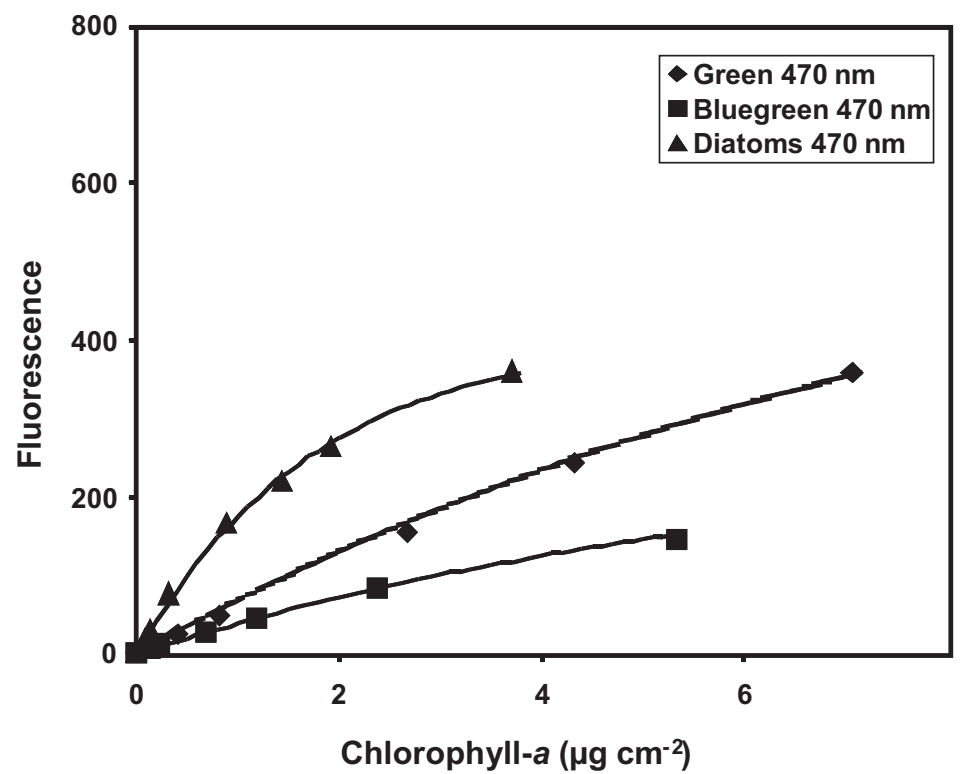

Fig. 3. Fluorescence intensities of three spectral algal groups at various concentrations at an excitation wavelength of $470 \mathrm{~nm}$. 
Table 1. The estimated $a_{\lambda k}$ coefficients, $1=$ green algae, $2=$ blue algae and $3=$ brown algae. $A_{\lambda k}$ are given in relative fluorescence intensities per chlorophyll-density of the samples $\left(\mu \mathrm{g} \mathrm{cm}^{-2}\right)$ at excitation wavelength $\lambda$.

\begin{tabular}{lclllll}
\hline & $370 \mathrm{~nm}$ & $470 \mathrm{~nm}$ & $525 \mathrm{~nm}$ & $570 \mathrm{~nm}$ & $590 \mathrm{~nm}$ & $610 \mathrm{~nm}$ \\
\hline $\mathbf{a}_{\lambda \mathbf{k}=\mathbf{1}}$ & 1 & 76.1 & 252.5 & 7.9 & 268.0 & 215.1 \\
$\mathbf{a}_{\lambda \mathbf{k}=\mathbf{2}}$ & 12.9 & -1.8 & 118.1 & 22.1 & 483.2 & 507.0 \\
$\mathbf{a}_{\lambda \mathbf{k}=\mathbf{3}}$ & 48.8 & 90.6 & 706.3 & 23.5 & 344.1 & 280.8 \\
\hline
\end{tabular}

$\mathrm{a}_{\lambda \mathrm{k}}$ were determined by measuring benthic samples with the benthic probe containing one algal group (Table 1).

After the measurement with the probe, these filters were then extracted in $100 \%$ acetone and the chlorophyll concentrations measured in the HPLC; method as described in WiLTSHIRE (2000).

The determination of the distribution of the spectral algal groups is based on the premise that the measured excitation spectrum at a fixed emission wavelength is a superposition of the signals from the individual cells and yellow substances (see BeUtLer et al. $2002 \mathrm{a}, \mathrm{b}$ ). For the total fluorescence intensity at a single excitation intensity we get equation (1)

$$
\mathrm{F}\left(\lambda_{\mathrm{ML}}\right)=\Sigma_{\mathrm{k}=1 \text { to n }} \mathrm{C}_{\mathrm{CHLa} \cdot \mathrm{k}} \mathrm{f}_{\lambda_{\mathrm{k}}} \mathrm{I}_{\mathrm{ML}}\left(\lambda_{\mathrm{ML}}\right)
$$

where: $\mathrm{C}_{\mathrm{CHLa} \cdot \mathrm{k}}$ is the concentration of Chl- $a$ which is contained in cells of the $\mathrm{k}$ 'th algal group (or yellow substances). $\mathrm{I}_{\mathrm{ML}}$ : the intensity of the measuring light (in $\mu \mathrm{E} \mathrm{m}^{-2} \mathrm{~s}^{-1}$ ). $\mathrm{f}_{\lambda \mathrm{k}}$ : fluorescence intensity of spectral k'th algal group at excitation wavelength $\lambda$ contained on the sample.

To obtain the algal concentration $\mathrm{C}_{\mathrm{Chl} \cdot \mathrm{k}}$ equation (2) was minimized by the use of the fit procedure of BEUTLER et al. (2002a).

$$
\mathrm{X}^{2}=\Sigma_{\lambda \mathrm{ML}}\left(\mathrm{F}_{\text {measured }}\left(\lambda_{\mathrm{ML}}\right) \cdot-\Sigma_{\mathrm{k}=1 \text { to n }} \mathrm{C}_{\mathrm{CHLa} \cdot \mathrm{k}} \mathrm{a}_{\lambda \mathrm{k}} \mathrm{I}_{\mathrm{ML}}\left(\lambda_{\mathrm{ML}}\right)\right)^{2}
$$

with $\mathrm{F}_{\text {measured }}\left(\lambda_{\mathrm{ML}}\right)$ : the measured fluorescence intensity of the sample at wavelength $\lambda_{\mathrm{ML}}$.

The method was found to be sufficiently linear in the laboratory, at chlorophyll densities below $5 \mu \mathrm{g} \mathrm{cm}^{-2}$, and with errors due to self shading of below $5 \%$. The $\mathrm{a}_{\lambda \mathrm{k}}$ factors used in the algorithms are given in Table 1 .

\section{Advanced calibration}

At first the BenthoFluor was calibrated only against three planktonic species of algae and chlorophyll quantities on filter surfaces were based on measurements of algal solutions using a cuvette multialgal fluorometer. For an advanced calibration, benthopelagic and purely benthic culture suspensions of microalgae, Navicula sp., Nitzschia sp., Stauroneis sp. (brown group); Staurastrum sp. (green group); Synechococcus sp. (blue group) in different con- 

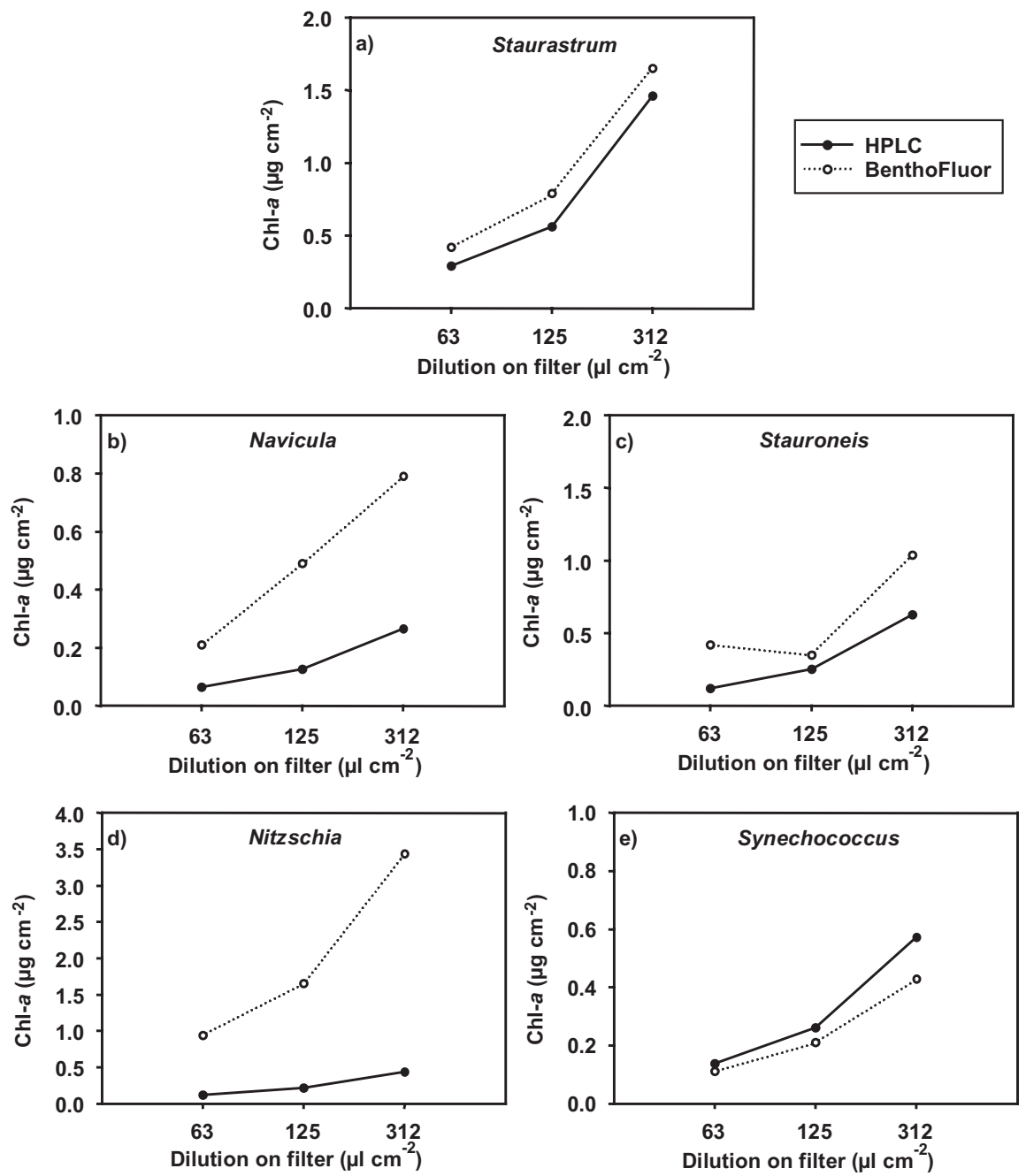

Fig. 4. Total chlorophyll- $a$ concentrations $\left(\mu \mathrm{g} \mathrm{cm}^{-2}\right)$ of different microalgae culture suspensions measured with HPLC and the BenthoFluor. Microalgal cultures measured: a) Staurastrum sp. (green group), b, c, d) Navicula sp., Stauroneis sp., Nitzschia sp., (brown group) and e) Synechococcus sp. (blue group).

centrations $\left(63-312 \mu \mathrm{cm}^{-2}\right)$, were filtered onto Whatman GFF filters and measured with the probe. After the measurement with the probe the filters were this time extracted in $100 \%$ acetone and the chlorophyll concentrations measured in the HPLC using the methods of WiLTSHIRE (2000). Examples of the relationships between the HPLC data and the probe are depicted in Fig. 4.

Our results showed that the calibration of the probe was not optimal as for all the algae the slopes of the chlorophyll relationships obtained from both 
Table 2. Calibration of the BenthoFluor with benthic and benthopelagic microalgae. Algal culture, algal type, slope, intercept and $r^{2}$ of the chlorophyll concentrations of single culture.

\begin{tabular}{lllll}
\hline & Algal type & Slope & Intercept & $r^{2}$ \\
\hline Synechococcus sp. & Green & 0.55 & 0.06 & 0.97 \\
Staurastrum sp. & Blue-green & 0.89 & 0.25 & 0.99 \\
Stauroneis sp. & Diatoms & 2.90 & -0.26 & 0.90 \\
Navicula sp. & Diatoms & 3.35 & 0.00007 & 0.98 \\
Nitzschia sp. & Diatoms & 7.85 & -0.02 & 0.99 \\
\hline
\end{tabular}

methods showed strong differences (Table 2). Constant patterns of over- or underestimation of chlorophyll concentrations when using HPLC methods or the BenthoFluor could thus not be obtained. A good agreement between both methods was achieved in case of two benthic diatom species (brown group) shown in Fig. $4 \mathrm{a}+\mathrm{c}$. Other data showed that at times the HPLC values were much higher than those values measured and fitted using the initial algorithms of the probe (Fig. 4e). Normally the HPLC values were lower.

This information was used to fine tune the calibration of the probe to the actual chlorophyll concentrations in the algal layer on the filter. The new factors were then used in the algorithms given in Table 1.

\section{Examples of application}

In order to evaluate the applicability of the new benthic probe to natural situations, in particular in view of the pre-calibration, we carried out a series of tests. The first involved culturing benthic microalgae from sublittoral sediments under standard laboratory conditions and measuring these. The second was to test the measurement efficiency on natural, benthic algal assemblages and the third was to evaluate the probes performance to detect migration patterns on intertidal sediments.

\section{Application on sublittoral sediment cultures}

In order to test whether the BenthoFluor could be used to detect changes in microphytobenthos populations over time, mixed freshwater and marine microphytobenthic mats were grown under laboratory conditions. This was done by sieving natural sediments from the field into experimental units and incubated under controlled conditions (16 hours light/8 hours dark cycle with constant water flow) for 21 days. The fluorescence measurements were conducted by laying the measuring chamber on top of the sediment and, after a short dark-adaptation time, measuring the chlorophyll- $a$ concentrations per 

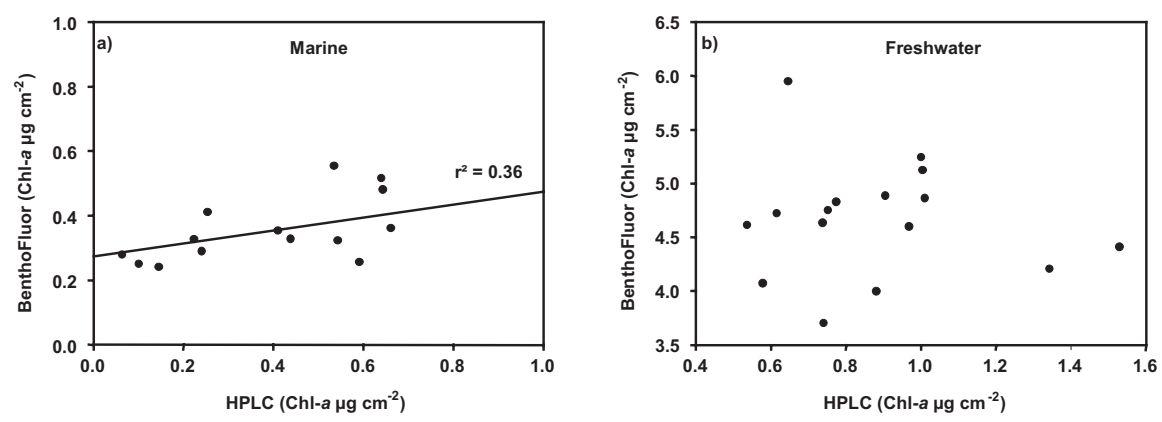

Fig. 5. Correlation of chlorophyll- $a$ concentrations $\left(\mu \mathrm{g} \mathrm{cm}^{-2}\right)$ obtained from HPLCand fluorometric measurements in the marine (a) and the freshwater (b) incubations.

spectral algal group using the probe. In addition, surface sediments were sampled from the same units in order to measure the chlorophyll- $a$ concentrations at the sediment surface (top $0-240 \mu \mathrm{m}$ ) via HPLC. The micro-slicing of the sediment surface was carried out using a cryomicrotome according to Wiltshire (2000). Measurements were made at the outset of the experiment and after 21 days in order to determine if the probe could be used for differentiating temporal microphytobenthos population shifts in both freshwater and marine benthic systems. The correlation between HPLC- and fluorescencemeasurements is given in Fig. 5.

Within the marine incubations the chlorophyll- $a$ concentrations detected ranged from 0.06 to $0.66 \mu \mathrm{g} \mathrm{cm}^{-2}$ (HPLC) and 0.24 to $0.56 \mu \mathrm{g} \mathrm{cm}^{-2}$ (BenthoFluor) (Fig. 5 a) and a significant correlation between both methods was achieved. The freshwater sediment, however, showed much higher concentrations and no correlation between both methods was found. Chlorophyll- $a$ concentrations in the freshwater incubations ranged from 0.53 to $1.53 \mu \mathrm{g} \mathrm{cm} \mathrm{cm}^{-2}$ (HPLC) and 3.71 to $5.95 \mu \mathrm{g} \mathrm{cm}^{-2}$ (BenthoFluor) (Fig. $5 \mathrm{~b}$ ). The strong deviation between both methods was most likely related to the thick biofilms in the freshwater incubations. In this case the results of both methods were non satisfying as HPLC analysis showed an underestimation of the actual algal biomass on the sediment surface and the measured concentrations obtained with BenthoFluor are rather high, thus, alluding to an over amplification of the sensor when the thickness of the biofilm limits the accuracy of the method.

The population differentiation of the microphytobenthos with the BenthoFluor showed that the chlorophyll contents of the marine sediments initially comprised mainly of diatom (99\%) and only $1 \%$ was represented by cyanobacteria (Fig. 6 a). The accuracy of the population differentiation was confirmed by pigment analyses via HPLC. After three weeks the community shifted to a three-constituent-community comprising of cyanobacteria, chlorophyta and diatoms (Fig. 6). In the freshwater incubations no green algae were 


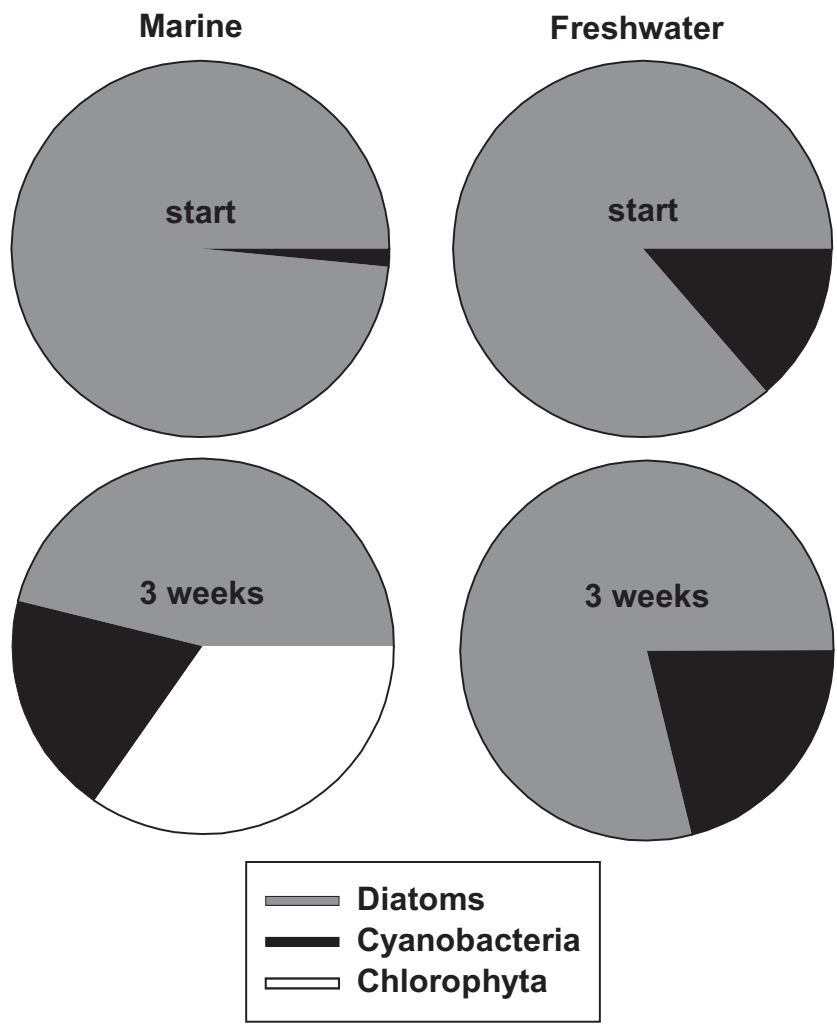

Fig. 6. Major taxonomic components of the microphytobenthos in the marine (left) and the freshwater (right) incubations given as proportions (\%) from the total algal at the beginning (top) and after 21 days (bottom) of incubation.

detected and the sediment microflora comprised of diatoms and cyanobacteria. After three weeks the proportion of cyanobacteria increased. The incubations with natural microphytobenthic communities showed that the BenthoFluor was useful in following temporal changes in both marine and freshwater mats.

\section{Application on intertidal algal assemblages}

The BenthoFluor was tested on natural emerged intertidal sediments at neighbouring sites in the German Wadden Sea (Dorum; Lower Saxony, Weser estuary, Germany). Based on the colour intensity, optically different sites were chosen. The sites were coloured light brown to dark brown and they all were situated within an area of $20 \mathrm{~m}^{2}$. The total chlorophyll- $a$ concentrations at each site were first detected with the BenthoFluor. These measurements were verified with HPLC, using samples taken with the Cryolander method (WILTSHIRE et al. 1997) and the micro-sliced surface layer (the top $0-240 \mu \mathrm{m}$ ), see meth- 


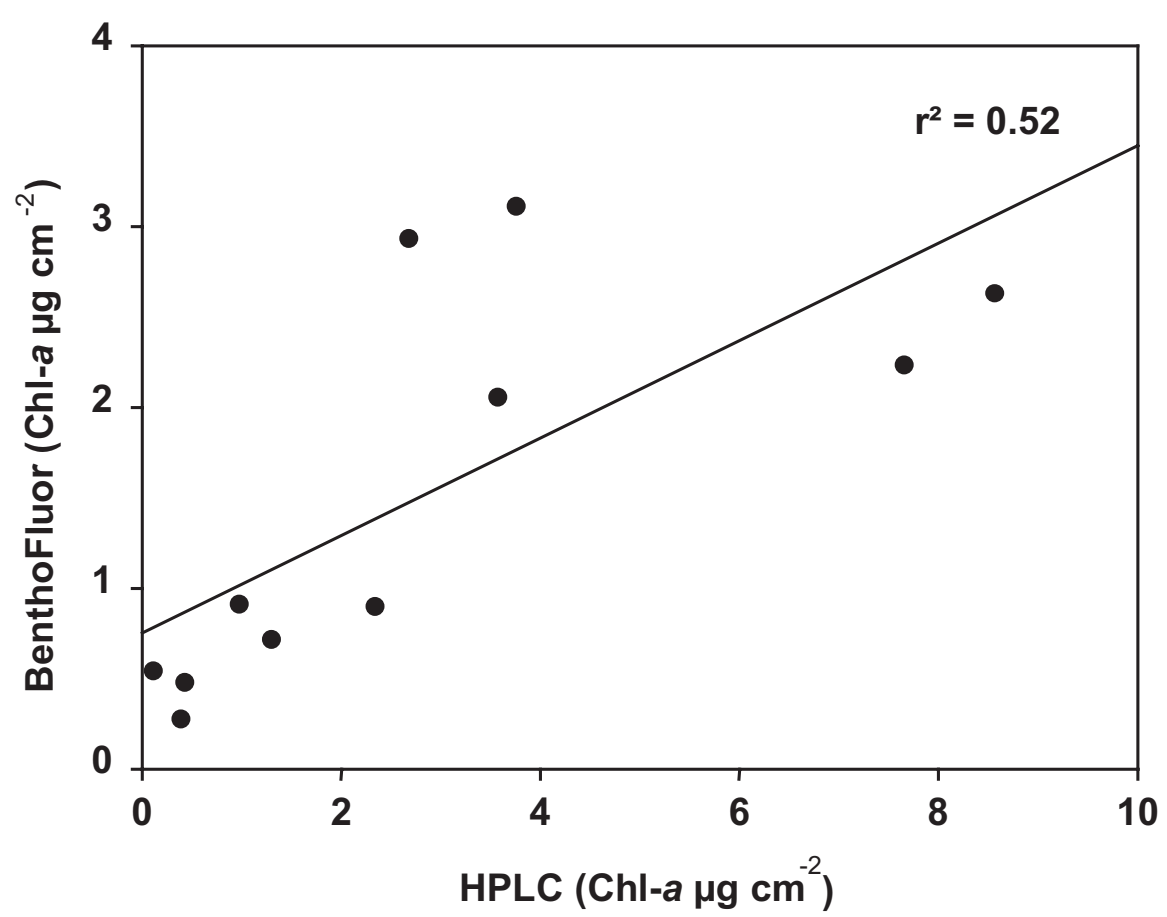

Fig. 7. Correlation of chlorophyll- $a$ concentrations $\left(\mu \mathrm{g} \mathrm{cm}^{-2}\right)$ obtained from HPLCand fluorometric measurements at an intertidal flat (Dorum, Wadden Sea).

ods as described by WiLTSHIRE (2000). Chlorophyll- $a$ concentrations ranged from 0.11 to $8.56 \mu \mathrm{g} \mathrm{cm}^{-2}$ (HPLC) and 0.28 to $3.11 \mu \mathrm{g} \mathrm{cm}^{-2}$ (BenthoFluor). When measured with the BenthoFluor the sites were shown to be very similar in their algal make-up as a dominance of diatoms was observed for all sediment surfaces and this was verified by the pigments found in the chromatograms of the HPLC analyses. The correlations of the HPLC values with the probe are given in Fig. $7\left(\mathrm{r}^{2}=0.52\right)$.

\section{Application to detect migration patterns}

One interesting example of use of the new probe is the in situ measurement of migration patterns of benthic algae to and away from sediment surfaces related to light, tides, rain etc. (PATERSON et al. 1998, UNDERWOOD et al. 1999). In order to follow migration patterns, a sediment area of $0.25 \mathrm{~m}^{2}$ was chosen and three spots within this plot were marked in order to perform parallel measurements with the BenthoFluor at each time interval. The error bars indicate the parallel measurements within the $0.25 \mathrm{~m}^{2}$ plot. At each time interval the same three spots were measure in order to guarantee that the same algae patches 


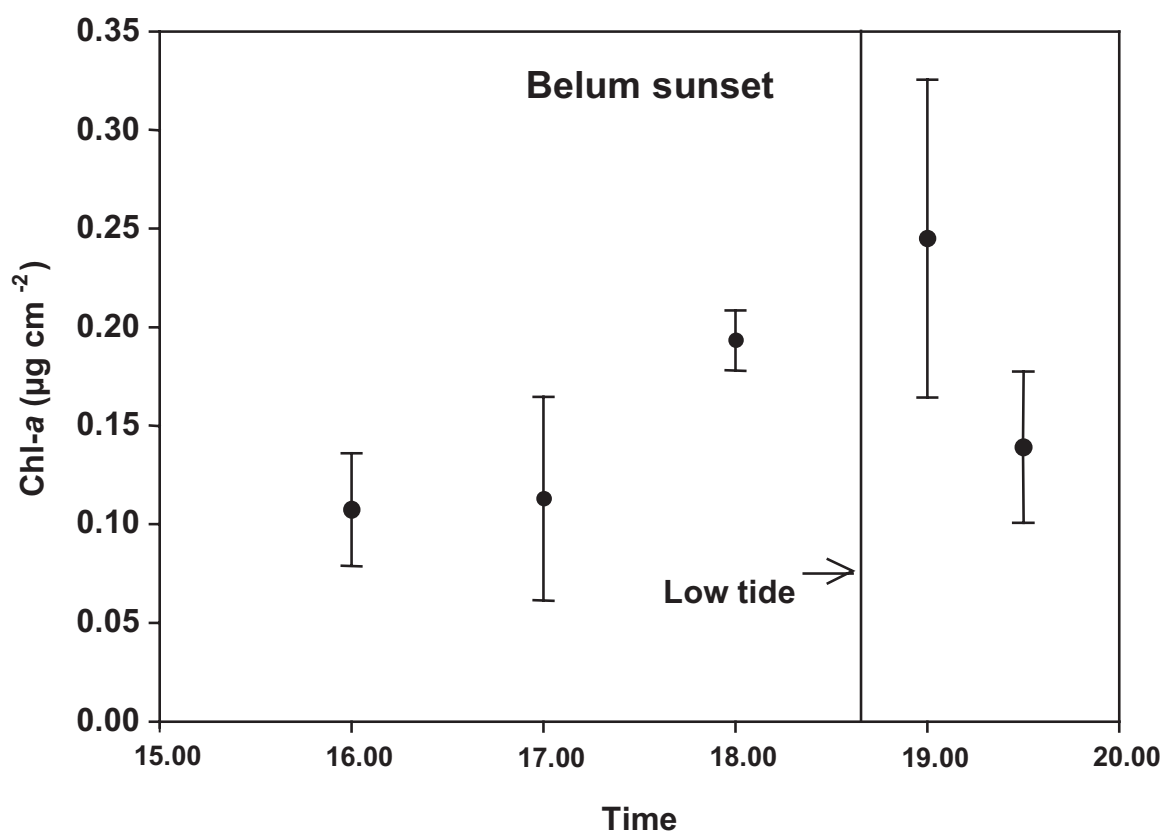

Fig. 8. Migration patterns detected from chlorophyll- $a$ measurements $\left(\mu \mathrm{g} \mathrm{cm}^{-2}\right)$ with the probe in the Elbe Estuary (Belum) during a time period starting 2.5 hours before and ending 1 hour after low tide around sunset.

were measured again. Depicted in Fig. 8 is the change in chlorophyll concentrations at the surface of sediment measured over the course of four hours during sunset at an intertidal flat in the Wadden Sea (Belum, Lower Saxony, Elbe estuary, Germany). The measurements were started 2.5 hours before low tide. At the beginning of the measurements concentrations of $0.11 \mu \mathrm{g} \mathrm{cm}^{-2} \pm 0.03$ were detected which increased continuously over exposure time to values of $0.25 \mu \mathrm{g} \mathrm{cm}^{-2} \pm 0.08$ at just around low tide. Right before the tide came in, the concentrations at the sediment surface decreased to values of $0.14 \mu \mathrm{g} \mathrm{cm}^{-2} \pm$ 0.04 and this phenomenon was related to the migration behaviour of benthic microalgae, a means of escaping erosion by tidal movement. Thus, the migration of the algae to and from the sediment surface from deeper layers was successfully monitored using the new probe. The probe is well suited for temporal resolutions and the data indicate that it will be useful at differentiating successional shifts in algal groups at the sediment surfaces over the course of the daily light rhythms. 


\section{Discussion}

The aim of this work was to apply the concepts of multialgal fluorometry (BEUTLER et al. 2002 b) to a benthic fluorometer. Taking into account the variety of sediments measured under laboratory and under field conditions, the applicability of the BenthoFluor prototype in determining algal populations on sediments in situ was successfully tested. However, we also found that depending on the different sediment types and environmental conditions the reliability of the probe needs to be checked for accuracy and if necessary recalibrated against standard chlorophyll techniques (e. g. HPLC analysis) prior to extensive measurement campaigns. In addition, we found that calibrating such a device is far from trivial and should ideally be an ongoing process. For a series production of the BenthoFluor it could be conceived that a data bank of measurements should automatically be set up in the instrument software with exact chlorophyll concentrations (measured by HPLC) in the uppermost $0-200 \mu \mathrm{m}$ of sediments and ideally also with cell counts, whereby the weighting factors for the algorithms be revaluated to guarantee a high accuracy. The data also shows that at higher chlorophyll concentrations on the sediment surface an over control of the device makes the measurements unreliable. It should be investigated if this problem could be alleviated by using a linear fit at lower concentrations and an exponential fit at higher concentrations.

The preliminary calibration of such a device should be with mean factors for as many benthic algal mats and as many different substrates as possible. It does not suffice to calibrate it with the usual algal standards or against a standardized instrument, as is often carried out for pelagic multialgal fluorometers. The instrument obtained from bbe Moldaenke could be easily recalibrated. Under no circumstances should the device be calibrated using wet chemical techniques (e.g. spectrophotometric measurements) for chlorophyll estimation as these methods are, particularly for sedimentary systems, extremely prone to error (see WILTSHIRE 2000).

Our approach can be used to monitor algal assemblage composition on sediments and it is an ideal tool for investigations on large-scale spatial and temporal variation of algal populations in sediments. It was, until now, not possible to carry out such detailed investigations of algal assemblage structures in surface sediments within a reasonable time frame. Furthermore, the BenthoFluor could easily be used to characterize the degree of patchiness of sediments, an aspect which is especially important for ground-truthing purposes.

All measurements on sediments, apart from PAM measurements (BARRANGUET \& Kromkamp 2000, SERodio et al. 2001, Glud et al. 2002), are retrospect. But spectral differentiation with PAM measurements on benthic systems has not been carried out in the literature so far. The results, particularly of long-term sediment incubations, show that the domination of algae in sedi- 
ment assemblages change rapidly (weeks) and that they not only comprise diatoms, which is often assumed. Past research showed that strong seasonality patterns occur in microphytobenthic communities and that, under certain circumstances, cyanobacteria and chlorophytes can contribute substantially to the sediment microflora (AgATZ et al. 1999, RiethMuELLER 2002). Thus, the current resolution of three algal groups is useful and it enables in situ differentiations of algal assemblages. However, the accuracy of the algal group differentiation is probably limited by the species-dependent variability within each individual algal group and by the influence of environmental factors on the fluorescence yield. Apart from the advantages of in situ differentiation and determination of total algal biomasses, we with this device could rapidly discern differences without having to wait for the analyses. Variations in the relationship between fluorescence and biomass at different light conditions might be a problem when comparing measurements conducted under different light intensities and seasons. However, this could be resolved by calibrations of fluorescence-biomass relationships at different light intensities.

Furthermore, with its in situ practicality the sensor was well suited to monitoring migration events of microalgae to and from the sediment surface, from deeper layers. This has been done a few times using reflectance measurements and fluorescence measurements (MAzel 1997, PAterson et al. 1998). However the methods used were cumbersome. Our probe will also be useful when it comes to differentiating tidal and diurnal succession of populations, i. e. the replacement of diatoms at a sediment surface during the course of exposure by green algae or euglenids (PATERSON et al. 1998). The sensor could be used for long-term monitoring programmes of chlorophyll- $a$ concentrations related to different spectral groups of algae in sediments over large spatial and temporal scales. This would be of considerable use for ground-truth measurements in remote sensing.

\section{Conclusions}

Our new method represents a unique approach to the qualitative and quantitative assessment of microphytobenthos in situ, with high spatial and temporal resolution, enabling a rapid evaluation of the community structure and its distribution. In addition, the new method can serve as a tool for long-term experimental investigations. In our case marine and freshwater incubations served as an ideal experimental unit to test this technique under laboratory conditions prior to field deployments. Hence, this approach could become an important new tool in aquatic benthic ecology and in the management of benthic aquatic resources. We also envisage that the device could be implemented on Landers in the submerged intertidal or in shallow lake systems where benthic micro- 
phytobenthic communities are a rather underestimated but nevertheless a highly productive community. Further developments and measurement refinements will permit a more detailed classification of algal groups in future.

\section{Acknowledgements}

We wish to thank Detlev Lohse and Florian Schulz (bbe Moldaenke, Kiel, Germany) for the support in technically realising our ideas and ARNe MALZAHN for assistance with the measurements. We are grateful to WINFRIED LAMPERT for his continued support of our work. This project was partially funded by the German Research foundation (DFG-Project WI 1810/2-1) and by the EU-project HIMOM.

\section{References}

Admiraal, W. \& Peletier, H. (1980): Distribution of diatom species on an estuarine mud flat and experimental analysis of the selective effect of stress. - J. Exp. Mar. Biol. Ecol. 46: 157-176.

Agatz, M., Asmus, R. M. \& Deventer, B. (1999): Structural changes in the benthic diatom community along a eutrophication gradient on a tidal flat. - Helg. Mar. Res. 2: 92-101.

BARRANGUet, C. \& Kromkamp, J. (2000): Estimating primary production rates from photosynthetic electron transport in estuarine microphytobenthos. - Mar. Ecol. Prog. Ser. 191: 163-174.

Beutler, M., Wiltshire, K. H., Meyer, B., Moldaenke, C. \& Dau, H. (2001): In situ profiles of phytoplankton: Algal composition and biomass determined fluorometrically. - In: Hallegraeff, Blackburn, J., Bolch \& Lewis, M. R. (eds), Ninth Conference on Harmful Algal Blooms, pp. 202-205.

Beutler, M., Wiltshire, K. H., Luering, C., Moldaenke, C. \& Lohse, D. (2002 a): Fluorometric depth-profiling of chlorophyll corrected for yellow substances. - Conference Proceedings of Aquaculture, Environment and Marine Phytoplankton. pp. 231-238.

Beutler, M., Wiltshire, K. H., Meyer, B., Moldaenke, C., Luering, C., Meyerhoeffer, M., Hansen, U. P. \& DaU, H. (2002 b): A fluorometric method for the differentiation of algal populations in vivo and in situ. - Photosynth. Res. 72: 3953.

Colijn, F. \& De Jonge, V. N. (1984): Primary production of microphytobenthos in the Ems-Dollard Estuary. - Mar. Ecol. Prog. Ser. 14: 185-196.

Cullen, J. J., Ciotti, A. M., Davis, R. F. \& Lewis, M. R. (1997): Optical detection and assessment of algal blooms. - Limnol. Oceanogr. 42: 1223-1239.

FERON, P. (1993): Optical fibre spectrometry for in situ algae discriminations. - Spie 2048: $147-152$.

Glud, R. N., Rysgaard, S. \& Kuehl, M. (2002): A laboratory study on $\mathrm{O}_{2}$ dynamics and photosynthesis in ice algal communities: Quantification by microsensors, $\mathrm{O}_{2}$ exchange rates, ${ }^{14} \mathrm{C}$ incubations and a PAM fluorometer. - Aquat. Microb. Ecol. 27: $301-311$. 
Gorbunov, M. Y., Falkowski, P. G. \& Kolber, Z. S. (2000): Measurement of photosynthetic parameters in benthic organisms in-situ using a SCUBA-based fast repetition rate fluorometer. - Limnol. Oceanogr. 45: 242-245.

Haeckel, E. (1890): Plankton Studien. - G. Fischer Verlag.

KIEFER, D. A. (1973): Fluorescence properties of natural phytoplankton populations. Mar. Biol. 22: 263-269.

KolbOWSKI, J. \& SCHREIBER, U. (1995): Computer-controlled phytoplankton analyzer based on a 4-wavelength PAM chlorophyll fluorometer. - In: MATHIS, P. (ed.): Photosynthesis: From Light to Biosphere. - Kluwer, pp. 825-828.

Kromkamp, J., Barranguet, C. \& Peene, J. (1998): Determination of microphytobenthos PSII quantum efficiency and photosynthetic activity by means of variable chlorophyll fluorescence. - Mar. Ecol. Prog. Ser. 162: 45-55.

Mazel, C. (1997): Diver-operated instrument for in situ measurements of spectral fluorescence and reflectance of marine benthic organisms and substrates. - Opt. Engineering 36: 2612-2617.

Murphy, R. J., Tolhurst, T. J., Chapman, M. G. \& Underwood, A. J. (2004): Estimation of surface chlorophyll on an exposed mudflat using digital colour-infrared (CIR) photography. - Est. Coast. Shelf Sci. 59: 625-638.

Paterson, D. M., Wiltshire, K. H., Miles, A., Blackburn, J., Davidson, I., YATes, M. G., McGrorty, S. \& Eastwood, J. A. (1998): Microbiological mediation of spectral reflectance from intertidal cohesive sediments. - Limnol. Oceanogr. 43: $1207-1221$.

Revsbech, N. P. \& Joergensen, B. B. (1983): Photosynthesis of benthic microflora measured with high spatial resolution by the oxygen microprofile method capabilities and limitations of the method. - Limnol. Oceanogr. 28: 749-756.

Revisber, N. P., Joergensen B. B. \& BRIX, O. (1981): Primary production of microalgae in sediments measured by oxygen microprofile ${ }^{14} \mathrm{C}$ labeled bicarbonate fixation and oxygen exchange methods. - Limnol. Oceanogr. 26: 717-730.

Riethmueller, R., Heineke, M., Kuehl, H. \& Keuker-Rudiger, R. (2000): Chlorophyll- $a$ concentration as an index of sediment surface stabilisation by microphytobenthos? - Cont. Shelf Res. 20: 1351-1372.

Schreiber, U., Schliwa, U. \& Bilger, W. (1986): Continuous recording of photochemical and non-photochemical chlorophyll fluorescence quenching with a type of modulation fluorometer. - Photosynth. Res. 10: 51-62.

Serodio, J., Da Silva, J. M. \& CATARino, F. (1997): Nondestructive tracing of migratory rhythms of intertidal benthic microalgae using in vivo chlorophyll a fluorescence. - J. Phycol. 33: 542-553.

- _ - (2001): Use of in vivo chlorophyll a fluorescence to quantify short-term variations in the productive biomass of intertidal microphytobenthos. - Mar. Ecol. Prog. Ser. 218: 45-61.

Underwood, G. J. C., Nilsson, C., Sundbaeck, K. \& WulfF, A. (1999): Short-term effects of UVB radiation on chlorophyll fluorescence, biomass, pigments, and carbohydrate fractions in a benthic diatom mat. - J. Phycol. 4: 656-666.

Utermoehl, H. (1958): Zur Vervollkommnung der quantitativen PhytoplanktonMethodik. - Mitt. Internat. Verein. Limnol. 9: 1-38.

van Kooten, O. \& Snel, J. F. H. (1990): The use of chlorophyll fluorescence nomenclature in plant stress physiology. - Photosynth. Res. 25:147-150. 
WiLtshire, K. H. (2000): Algae and associated pigments of intertidal sediments, new observations and methods. - Limnologica 30: 205-214.

Wiltshire, K. H., Blackburn, J. \& Paterson, D. M. (1997): The Cryolander: A new method for fine-scale in situ sampling of intertidal surface sediments. - J. Sediment. Res. 67: 977-981.

Wiltshire, K. H. \& Schroeder, F. (1994): Pigment patterns in suspended matter from Elbe and associated waters as determined using high performance liquid chromatography. - Neth. J. Aquat. Ecol. 28: 255-265.

Yentsch, C. \& PhinNey, D. (1985): Spectral fluorescence: A taxonomic tool for studying the structure of phytoplankton populations. - J. Plankton Res. 7: 617632.

Yentsch, C. \& Yentsch, C. (1979): Fluorescence spectral signatures: The characterisation of phytoplankton populations by the use of excitation and emission spectra. - J. Mar. Res. 7: 617-632.

Submitted: 5 February 2006; accepted: 18 April 2006. 